\title{
Nanotechnological approaches for pentamidine delivery
}

\author{
Ilaria Andreana ${ }^{1} \cdot$ Valeria Bincoletto $^{1} \cdot$ Paola Milla ${ }^{1} \cdot$ Franco Dosio $^{1} \cdot$ Barbara Stella ${ }^{1} \odot \cdot$ Silvia Arpicco ${ }^{1}$
}

Accepted: 31 January 2022 / Published online: 25 February 2022

(c) The Author(s) 2022

\begin{abstract}
Pentamidine (PTM), which is a diamine that is widely known for its antimicrobial activity, is a very interesting drug whose mechanism of action is not fully understood. In recent years, PTM has been proposed as a novel potential drug candidate for the treatment of mental illnesses, myotonic dystrophy, diabetes, and tumors. Nevertheless, the systemic administration of PTM causes severe side effects, especially nephrotoxicity. In order to efficiently deliver PTM and reduce its side effects, several nanosystems that take advantage of the chemical characteristics of PTM, such as the presence of two positively charged amidine groups at physiological $\mathrm{pH}$, have been proposed as useful delivery tools. Polymeric, lipidic, inorganic, and other types of nanocarriers have been reported in the literature for PTM delivery, and they are all in different development phases. The available approaches for the design of PTM nanoparticulate delivery systems are reported in this review, with a particular emphasis on formulation strategies and in vitro/in vivo applications. Furthermore, a critical view of the future developments of nanomedicine for PTM applications, based on recent repurposing studies, is provided.
\end{abstract}

Keywords Pentamidine $\cdot$ Drug delivery $\cdot$ Liposomes $\cdot$ Nanoparticles $\cdot$ Repurposing

\section{Introduction}

Nanocarrier-based drug delivery has gained ever increasing amounts of attention in recent decades thanks to the characteristics that it can provide: increased drug solubility, modified pharmacokinetics, sustained release, tissue targeting, reduced toxicity, biosafety, and the ability to bypass biological barriers, which result in higher drug efficacy and bioavailability [1-3]. A plethora of different nanocarriers have been proposed for different diseases, such as cancer, central nervous system-related disorders, immune diseases, and, more recently, viral infections [4-7]. Proposed drug nanocarriers differ in their composition (mainly lipid, polymeric, or inorganic) and their structure (matrix or vesicular systems, including those with an aqueous, lipid, or gas core) and several incorporation strategies have been adopted, both for lipophilic and, sometimes, hydrophilic compounds, which is even more challenging $[8,9]$. Among the molecules that have been considered for nanoencapsulation, we can find pentamidine (PTM), which is a drug that was initially

Barbara Stella

barbara.stella@unito.it

1 Department of Drug Science and Technology, University of Turin, Via P. Giuria 9, 10125 Turin, Italy developed as a synthetic analogue of insulin and is now a Food and Drug Administration (FDA)- and European Medicines Agency (EMA)-approved molecule for the treatment of a range of parasitic infections (Table 1) [10,11].

PTM [1,5-bis(4-amidinophenoxy)pentane] (CAS Registry number 100-33-4) (Fig. 1) is an aromatic diamidine, which has been marketed in the form of two salts, isethionate [bis(2-hydroxyethane-1-sulfonic acid)] and mesylate [bis(methanesulfonic acid)], and is administered via the intravenous (i.v.) and intramuscular routes (i.m.) and via inhalation [12, 13]. Its chemical and physical properties indicate that PTM is a solid (melting point $186^{\circ} \mathrm{C}$, decomposes) that is completely water soluble at $25{ }^{\circ} \mathrm{C}(0.0236 \mathrm{mg} / \mathrm{mL}$, predicted) with a $\log \mathrm{P}$ of 4 (experimental) and a $\mathrm{pKa}$ of 12.13 (predicted) [14]. At physiological pH, both amidine groups are positively charged, meaning that PTM has poor oral bioavailability $[15,16]$. Consequently, PTM is used i.v. in the treatment of trypanosomiasis, leishmaniasis, and Pneumocystis pneumonia (PCP), and is usually inhaled in aerosol form to prevent PCP in high-risk, HIV-infected patients [17-19].

Although PTM is widely used, its application as a curative strategy for infectious diseases and in new therapeutic options urgently requires approaches to improve its therapeutic efficacy, to overcome drug resistance, and to reduce the complications that are caused by its associated adverse 
Table 1 Commercially available products containing pentamidine isethionate

\begin{tabular}{llll}
\hline Name & Physical description & $\begin{array}{l}\text { Dosage as active } \\
\text { ingredient }(\mathrm{mg})\end{array}$ & Company \\
\hline Nebupent $^{\circledR}$ & Powder for solution & 300 & Fresenius Kabi, APP Pharmaceuticals \\
Pentacarinat $^{\circledR}$ & Lyophilized powder & $200 / 300$ & Aventis Pharma, Lepetit \\
Pentam $^{\circledR}$ & Powder for solution & 300 & Fresenius Kabi, APP Pharmaceuticals \\
Pneumopent $^{\circledR}$ & Lyophilized powder & 60 & Fisons Pharmaceuticals \\
Pentamidine isethionate & Powder for solution & $200 / 300$ & $\begin{array}{l}\text { Mayne Pharma, David Bull Laboratories, Taylor Pharmaceuticals, } \\
\text { Avet Pharmaceuticals, Seton Pharmaceuticals, Abbott } \\
\end{array}$ \\
& & Laboratories \\
\hline
\end{tabular}

Administration route: by inhalation or i.v. injection

effects [20]. The objective of this review is to discuss the advanced strategies that have been adopted to improve PTM delivery. Two different approaches have been developed to overcome the issues inherent in PTM use. The first is the synthesis of new PTM derivatives to provide compounds with better pharmaceutical activity, higher lipophilicity, and lower cytotoxicity. The most promising compounds have been tested in in vitro and in vivo models. This approach is out of the scope of this review. However, papers by Porcheddu et al. and Soeiro et al. provide a full description of the chemical modification methods and synthetic routes used to obtain PTM derivatives $[21,22]$. The second approach involves nanotechnology and is the topic of this review. Although not reported in this paper, microcapsules have also been proposed as a means to encapsulate PTM [23-26]; in these preliminary formulation studies, PTM was used as a model drug to analyze the influence of various preparation parameters on the physico-chemical characteristics of drug-loaded poly(lactide-co-glycolide) (PLGA) microparticles.

Herein, we will initially explore the previously approved and newly proposed therapeutic applications of PTM, focusing on its repurposing in cancer, as well as in brain and muscular disorders (Fig. 2). Secondly, we will consider the most relevant nanomedicine-based strategies that make use of the physico-chemical properties of PTM to overcome its drawbacks and increase its therapeutic compliance. An in-depth analysis of structure, composition, features, benefits, and uses has been conducted for these systems.

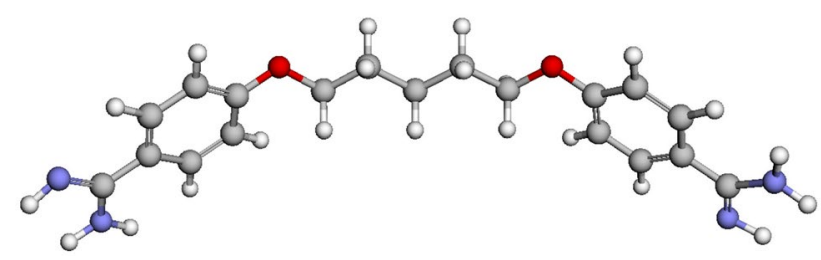

Fig. 1 Ball and stick representation of PTM structure (carbon atoms are gray, oxygen red, nitrogen light blue, hydrogen white) [14]

\section{Applications of PTM}

\section{Current PTM applications}

PTM was first synthesized in the late 1930s as a hypoglycemic drug against trypanosomes as it was observed that the parasites require glucose for their in vitro maintenance [12]. PTM has been used since the 1940s and is still one of the most frequently used drugs for the treatment of the first stage of human African trypanosomiasis and other neglected diseases, such as malaria and leishmaniasis [27]. Moreover, aerosolized PTM was approved for use in prophylaxis against PCP in HIV-infected patients who are at high risk when infected [28]. It has been reported that the benzamidine moiety is the essential pharmacophore of several commercially available drugs for the treatment of parasitic and fungal diseases; these compounds are characterized by a symmetrical structure in which the aromatic rings are separated by a short acyclic linker [29, 30].

Leishmaniasis and human African trypanosomiasis are infective and endemic diseases that affect the population the world over. Leishmaniasis incidence occurs mainly in three geographical regions (South-East Asia, Latin America, and East Africa) with a total number cases of up to 1.2 million [31, 32]. The parasites are transmitted to humans in the bites of infected female phlebotomine sandflies as a flagellated, metacyclic promastigote, which is phagocyted by host macrophages and then differentiates into non-flagellated, replicative amastigotes, culminating in the expression of clinical disease [33, 34]. Leishmaniasis is characterized by several different clinical manifestations: ulcerative skin lesions that develop at the site of the sandfly bite, multiple non-ulcerative nodules, destructive mucosal inflammation, and disseminated visceral infection [35]. The development of the disease is determined by the parasite's characteristics, vector biology, and host factors, such as immune response [33], and affects organs including the liver and spleen. Pentavalent antimonials, which have a narrow therapeutic index and whose use has largely been limited, are still the first-line 
Fig. 2 Approved and proposed therapeutic applications of PTM (created with BioRender.com)

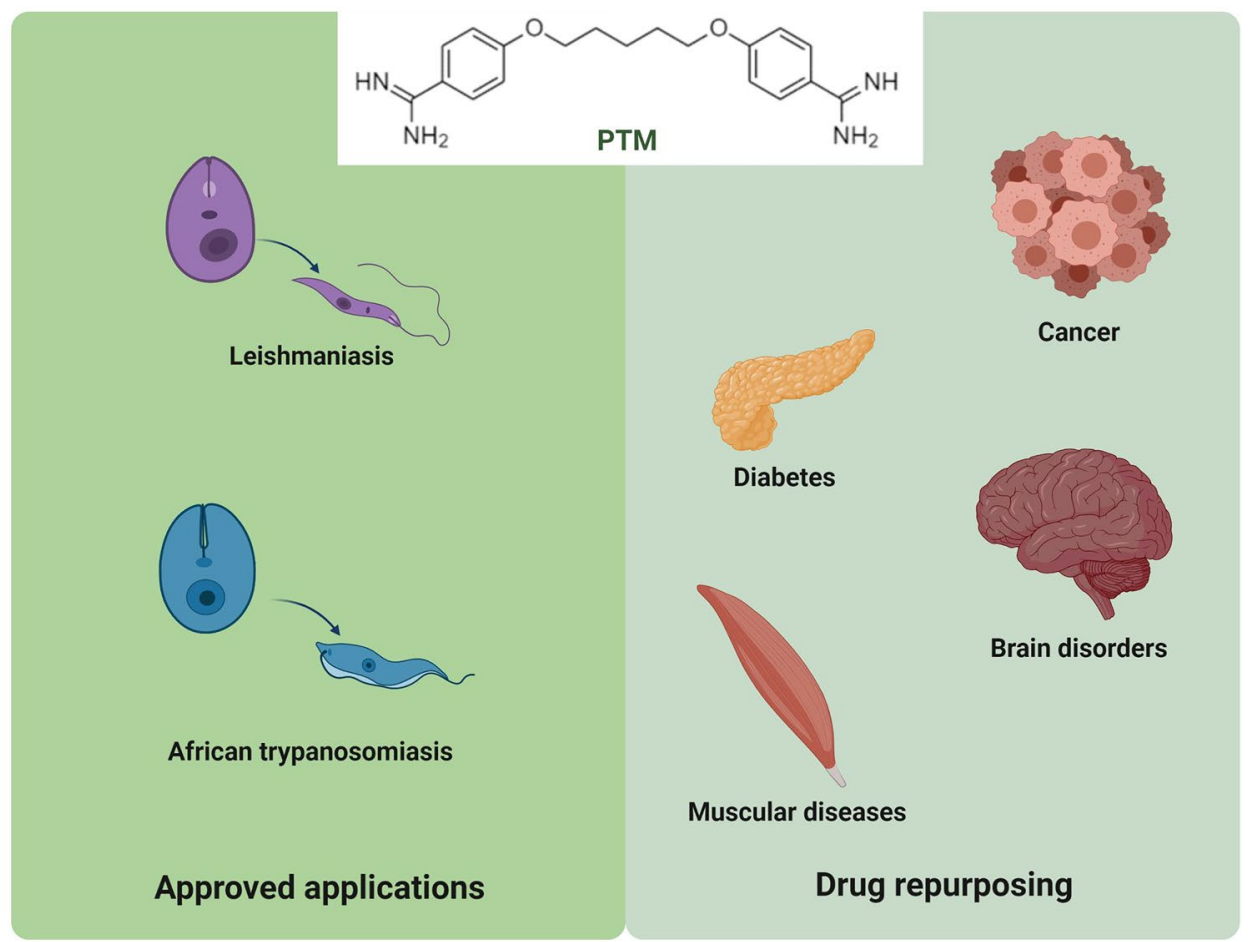

drugs in several parts of the world [36]. As a second choice, amphotericin B, PTM, and paromomycin are considered to be curative strategies. Amphotericin B is a highly efficacious antifungal drug, whose associated side effects are ameliorated in its liposomal formulation [37]. Over the years, paromomycin, an aminoglycoside antibiotic, has been used for the topical treatment of leishmaniasis, showing positive results in disease resolution [38]. Many clinically resistant cases have recently been found and treatment failure is an increasing problem. Technological and therapeutic approaches are urgently required if clinical outcomes are to be reached $[39,40]$. Although PTM has poor oral bioavailability and pharmacokinetic issues, it can be successfully used for drug-resistant leishmaniasis.

Despite the pharmaceutical drawbacks of PTM, it is also used in the treatment of African trypanosomiasis. Human African trypanosomiasis, also known as sleeping sickness, is considered a neglected disease. It is caused by infection with protozoan parasites that belong to the genus Trypanosoma, which is widespread in 23 African countries [41-43]. Trypanosomes are surrounded by a surface glycoprotein that is recognized by the host's immune system. Nevertheless, a few of the parasites have changed their surface protein to continue proliferating unnoticed by the immune system [44]. It is transmitted via the bite of the blood-sucking tsetse fly, which is a viviparous insect that deposits a fully developed larva, which then needs to become an adult fly and feeds on an infected mammalian host in order to evolve into the infective form. Only about
$0-1 \%$ of flies carries a mature infection that can be transmitted to another host [45]. The early stage of the pathology is characterized by headaches, weight loss, fever, and lymphadenopathy, which evolve into more serious symptoms that potentially involve the nervous system when the parasite crosses the blood-brain barrier (BBB) [46], producing neurological disturbances including sleep disorder, tremor of the hands, and motor weakness, and can lead to death if untreated [47]. The first-line therapeutic strategy in the early stage currently consists of suramin, melarsoprol, or PTM, although the application of PTM is limited because of its well-known side effects. In particular, hypoglycemia and hyperglycemia are the most common consequences of PTM therapy in patients affected by African trypanosomiasis [41, 48]. Hypoglycemia, with possible progression to insulin-dependent diabetes mellitus, has been reported in HIV-infected patients [49]. Moreover, PTM treatment may be accompanied by a prolongation of the QT interval on electrocardiograms and hypotension [50-52]. Other PTM side effects include abscesses at the site of intramuscular injection, abnormal liver function, pancreatic complications, nephrotoxicity, leucopoenia, thrombocytopenia, and hypocalcaemia [53-56].

\section{PTM repurposing}

As PTM is widely used in clinics and can be readily repurposed, it is the most studied member of the diamidines series, which is a class of compounds that can interfere 
with many biomolecular targets, meaning that they have been studied as potential drugs for the treatment of a variety of diseases, such as parasitic diseases, tumors, brain disorders (Alzheimer's and Parkinson's diseases), hypertension, diabetes, and muscular dystrophy [57]. Indeed, PTM has been investigated, alone and in combination with approved drugs (to foster the discovery of new antimicrobial synergies), in several screenings for the targeting of fungal, Gram-negative, and other pathogens [58-63]. In addition, PTM has recently been identified as a potential blocker of the SARS-CoV-2 3a-channel in a library of 2839 approvedfor-human-use drugs, although PTM activity is still to be tested on the whole virus [64].

The mechanism of action of PTM is not well understood despite all of these studies. It has been shown experimentally to interfere with numerous cellular processes [65]. PTM can act as an N-methyl-D-aspartate (NMDA) receptor antagonist, and thus displays neuroprotective effects [66, 67]. It is actively transported into trypanosomes and binds to DNA within the nucleus and kinetoplasts. Additionally, PTM interferes with polyamine synthesis, RNA polymerase activity, enters protozoan cells and binds to transfer RNA, and prevents the synthesis of proteins, nucleic acids, phospholipids, and folate. It is also known to be an antagonist of histone acetyltransferase and calmodulin [68, 69].

Recently, PTM has been reported to exhibit anticancer properties and has shown antiproliferative effects on various human cancer cell types, such as melanoma, prostate, ovarian, colon, breast, lung, and cervical cancers in in vitro and in vivo models. In these studies, several different sites of action were proposed for PTM, but the mechanism of its anticancer activity still remains elusive [70-78].

In another research field, PTM was the first small molecule proposed for the treatment of Dystrophia myotonica type 1 (DM1); it gave interesting initial results as it is able to reverse the splicing defects associated with myotonic dystrophy. Indeed, DM1 is a genetic disorder of autosomal dominant inheritance caused by pathological expansions of small DNA sequences $\left((\mathrm{CTG})_{\mathrm{n}}\right)$ of the DMPK gene. The expanded DNA sequences are transcribed into RNA triplets which aggregate in specific structures called nuclear foci. The unstable structures sequestrate the muscleblind protein (MBNL) in the nucleus, resulting in a local reduction of protein level and characteristic symptoms of DM1 [79]. Several compounds have been shown to bind (CUG) RNA and release the splicing factors. PTM was selected, together with aminoglycoside antibiotic neomycin $\mathrm{B}$, from a small library of RNA binding compounds using in vitro and in vivo studies. Results showed that PTM is capable of binding the minor groove of AT-rich DNA and of preventing the formation of CUG-MBNL aggregates [80]. Additionally, PTM has recently been indicated as a therapeutic candidate for cardiac defects in DM1 and Dystrophia myotonica type 2 using fly heart models (Drosophila). Unfortunately, its high toxicity at therapeutic dose in vivo prevented its clinical use [81].

\section{Administration, fate, and clinical trials of PTM}

Because of its toxicity, the pharmacokinetics of PTM has only been studied in patients and has best been described by open, two- or three-compartment models [82, 83]. After the i.v. and i.m. administration of $4 \mathrm{mg} / \mathrm{kg}$, the mean peak serum concentrations were found to be $0.6 \mathrm{mg} / \mathrm{L}$ and $0.2 \mathrm{mg} / \mathrm{L}$, respectively, with large volumes of distribution at steady-state of $821 \mathrm{~L}$ and $2724 \mathrm{~L}$, respectively. Multiple dosing results in progressive drug accumulation, and the steady-state was achieved after 8 days of i.v. therapy [83]. Mean plasma levels after 21 days of inhaled PTM isethionate at $600 \mathrm{mg} / \mathrm{day}$ via a nebulizer averaged $11.8 \pm 10 \mathrm{ng} /$ $\mathrm{mL}$ in patients with acute PCP [19]. PTM is approximately $70 \%$ protein bound and accumulates especially in the liver, spleen, kidneys, and adrenal glands [84]. Biliary excretion is the major elimination pathway for PTM, but release from the liver is slow (99\% of the absorbed PTM in the liver is still present $24 \mathrm{~h}$ after i.v. infusion), whereas renal elimination only accounted for 4 to $7 \%$ of the administered dose [85].

The following clinical trials have been carried out, or are currently ongoing, to investigate the use of PTM for the treatment of a range of diseases.

\section{I.v. administration}

An i.v. formulation of PTM isethionate, OCZ 103 OS, has been tested as a potential therapy for cancer, including colorectal, pancreatic, and non-small cell lung cancers. However, the development of this formulation appears to have been discontinued after some phase I/II trials were completed (NCT00809796 [86], NCT01378143 [87], NCT00810953 [88], and NCT01844791[89]) (source US National Library of Medicine clinicaltrials.gov).

\section{Oral administration}

An oral formulation of PTM isethionate is being developed for the treatment of liver diseases, including hepatocellular carcinoma, non-alcoholic steatohepatitis, alcoholic steatohepatitis, non-alcoholic fatty liver disease, and liver metastasis. To date, as far as we know, the oral formulation has only been tested in a phase I study in adult cirrhotic patients with early-stage hepatocellular carcinoma, and safety, pharmacodynamics, and pharmacokinetics data were presented at the 67th Annual Meeting of the American Association for the Study of Liver Diseases [90, 91]. 


\section{Local administration}

The topical administration of PTM in a silicone-based gel is currently being tested for the treatment of hypertrophic scars in a phase I clinical trial that is still recruiting (NCT03403621) [92].

Intralesional injections of PTM for the treatment of cutaneous leishmaniasis have been tested in phase II/III studies in combination with topical miltefosine or paromomycin (NCT03445897 and NCT03096457) [93, 94].

\section{PTM delivery approaches}

\section{PTM for parasitic diseases}

The formulation of antiprotozoal drugs with nanocarriers is currently highly regarded as a promising approach in the treatment of leishmaniasis and trypanosomiasis [95-97], for which nanocarriers of different matrixes have been demonstrated to be effective [98-100]. The strategies that have been used to encapsulate PTM with drug delivery systems for the treatment of parasitic diseases are discussed below, and the characteristics of the PTM-based formulations are summarized in Table 2 and Fig. 3.

\section{Liposomes}

Liposomes, as drug delivery systems, are vesicles composed of phospholipids organized in concentric bilayers that enclose one or more aqueous spaces. A description of the preparation methods and their characteristics can be found elsewhere [101, 102]. The advantage of using liposomes as vehicles is their rapid accumulation in phagocytic cells as they are recognized as foreign particles, allowing liposomes to enhance the non-specific host defense [103]. However, there are only a few studies on the encapsulation of PTM in liposomes for use against Leishmania and human African trypanosomiasis. Nevertheless, after several different in vitro tests, researchers have found that glycoside-bearing liposomes can be used as systems to deliver drugs to macrophages in vivo [104]. On this basis, Banerjee et al. have described how sugar-grafted liposomes were prepared and tested against leishmaniasis in hamsters. Golden hamsters were infected via the intracardial passage of strain AG 83 from an Indian kala-azar patient. Different types of sugars, including mannose, galactose, and glucose, were tested. These formulations were injected subcutaneously (s.c.) into each animal every 3 days for a total of four doses over 10 days. Mannose-grafted liposomes that encapsulated PTM isethionate reduced the parasite load of the spleen by $85.1 \%$, whereas liposomes without sugar lowered it by only $46.6 \%$. Consequently, mannose-grafted liposomes were found to be the most efficient PTM delivery system, compared to other sugar-grafted carriers and sugar-free vesicles [105].

In another study, PTM isethionate was loaded into liposomes and tested against Acanthamoeba, which is an opportunistic protozoan pathogen that can cause blinding keratitis and fatal granulomatous encephalitis. Liposomes were prepared via the dehydration-rehydration method using $\mathrm{L}-\alpha$-phosphatidylcholine and either cholesterol or ergosterol. The results showed that both liposomal cholesterol-PTM and ergosterol-PTM were about 10 times more effective than the free drug at preventing the binding of Acanthamoeba to human brain microvascular endothelial cells. Moreover, loaded liposomes were more effective at reducing parasitemediated human cell cytopathogenicity than free PTM [106].

\section{Polymeric nanoparticles}

The use of polymers has been widely investigated as they offer several advantages, such as controlled drug release, the protection of drugs against premature degradation, and surface engineering [107, 108]. Studies on PTM delivery have reported the applicability of polymeric nanoparticles as potential tools for the improvement of the drug's pharmacokinetics and pharmacodynamics drawbacks [109]. In one of the first studies on the encapsulation of anti-Leishmania therapeutic agents into polymeric nanoparticles, Gaspar et al. described the ability of polyalkylcyanoacrylate nanoparticles to reduce the effective dose $\left(\mathrm{ED}_{50}\right)$ of primaquine. Increased effectiveness was demonstrated in vitro in macrophages infected with the Leishmania parasite, compared to free primaquine [110]. The emerging knowledge of nanomedicine and the potential applicability of PTM have led to the same technological approach being studied and activity investigations being performed on the formulation of PTM with different acrylate nanoparticles. Optimized formulations of PTMloaded methacrylate nanoparticles (mean size: $350 \mathrm{~nm}$ ) were firstly tested in vitro using a strand of Leishmania major MON 25 and monocytes U 937, with increased drug efficacy being reported, compared to the free drug [111]. These interesting results led to Fusai et al. describing PTM-loaded polymethacrylate nanoparticles and their efficacy in vivo. The nanoparticles were first prepared via the emulsion polymerization technique using PTM isethionate, based on electrostatic interactions between drug and polymer [112]. Subsequently, in vivo studies on BALB/c inbred mice were performed to confirm the superior effectiveness of the PTM-loaded nanoparticles. The mice that were administered the free drug by i.v immediately showed side effects, while in the group that received drugloaded nanoparticles there was no evidence of shock after the injection. The state of infection was evaluated after 


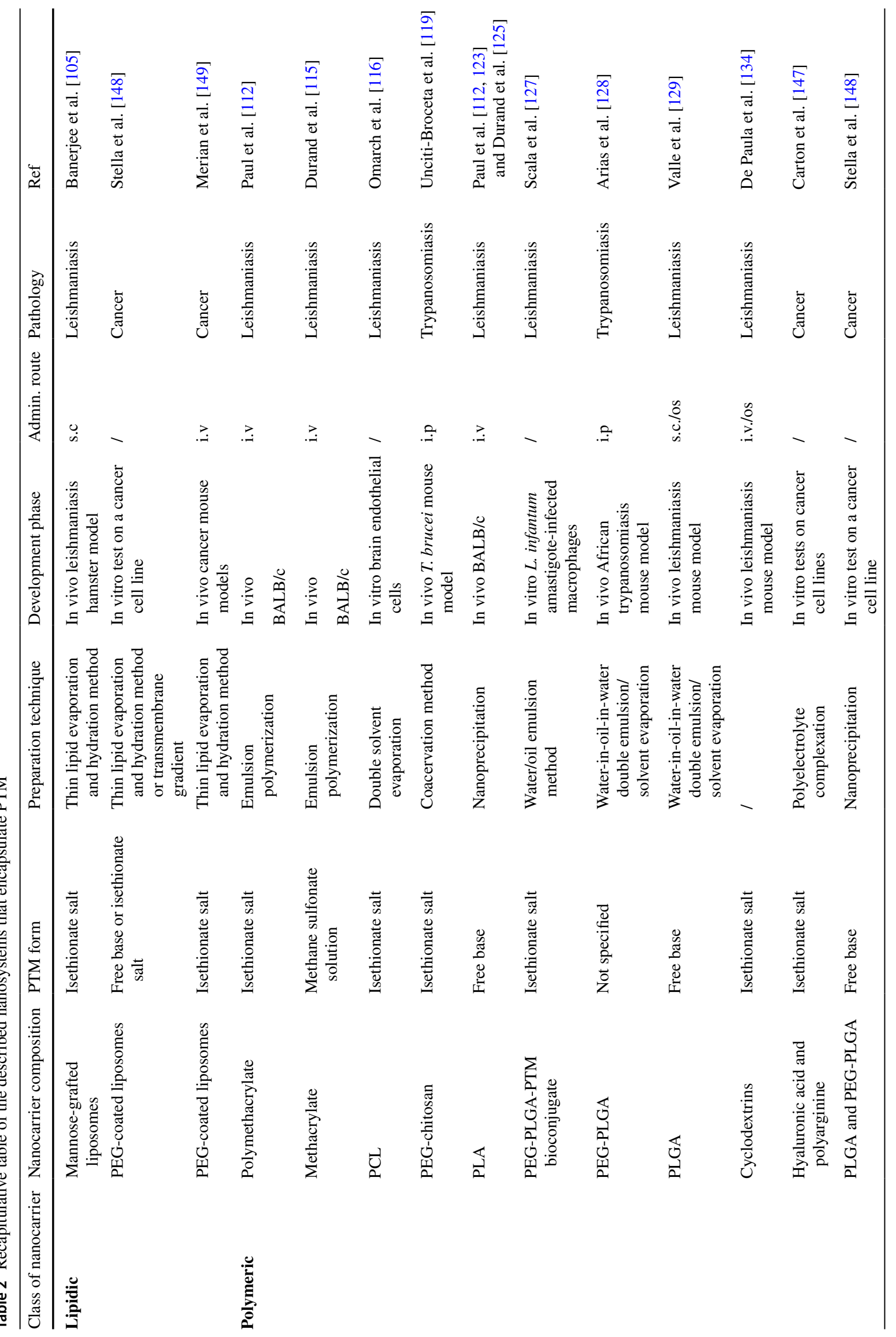


21 days by counting the number of amastigotes in the liver. Seventy-seven percent parasite suppression was reported in the group treated with loaded nanoparticles relative to the control group [113, 114]. Due to the increased interest in polyacrylate nanoparticles, Durand et al. have tested the activity of PTM-loaded methacrylate nanoparticles on a Leishmania infantum mouse model. The efficacy of encapsulated PTM against a different form of Leishmania was confirmed by the low value of $\mathrm{ED}_{50}$ obtained, demonstrating the ability of methacrylate nanoparticles to increase the efficacy of PTM and reduce side effects [115]. Nevertheless, the main problem of acrylate nanoparticles is their low biodegradability, which can be inconvenient for in vivo administration.

Moving on to other polymers, recent studies have involved the use of polycaprolactone polymer (PCL) loaded with PTM to enhance permeation through the BBB. PTMloaded PCL nanoparticles were obtained using the double solvent evaporation method and their physiochemical characteristics were evaluated. Their spherical shape decreased from 345 to $270 \mathrm{~nm}$ after complexation with PTM, with a negative zeta potential value of around $-30 \mathrm{mV}$ and $12 \%$ drug release over a period of $24 \mathrm{~h}$. The integrity of the BBB was evaluated in vitro on brain endothelial cells after loaded and unloaded nanoparticles were added; no significant tight junction alterations were observed, while loaded nanoparticles were shown to transport $66 \%$ of the PTM across the BBB [116].

Drug resistance, which complicates the management of Leishmania and African trypanosomiasis, is an important issue in the treatment of parasitic diseases [117, 118]. African trypanosome is generally covered by a single variant surface glycoprotein, termed VSG [42]. Combining PTM with targeted drug delivery systems overcomes possible drug resistance by taking advantage of the delivery systems' enhanced absorption into target cells, which is caused by surface engineering. Based on the chemical and biological structure of the infective parasite, Unciti-Broceta et al. have developed PEGylated chitosan nanoparticles that are surface-targeted with nanobodies that are able to specifically recognize specific VSG regions on a parasitic surface [119]. Indeed, these nanobodies are small enough to be able to infiltrate the dense parasite VSG coat and specifically recognize conserved epitopes common to the majority of the VSG molecules [120]. To this aim, nanobodies were coupled to the PEGylated PLGA nanoparticles via the EDC/ NHS chemistry. Nanoparticles were obtained using coacervation methods and by selecting the right PEG chain length to allow the nanobodies to bind onto the parasitic membrane. Spherical-shape nanoparticles had a size of around $135 \mathrm{~nm}$ and a negative zeta potential value for both loaded and blank nanoparticles, meaning that PTM was completely loaded inside chitosan nanoparticles. In vitro drug release 
Fig. 3 Nanocarriers proposed for the delivery of PTM in different therapeutic approaches (created with BioRender.com)

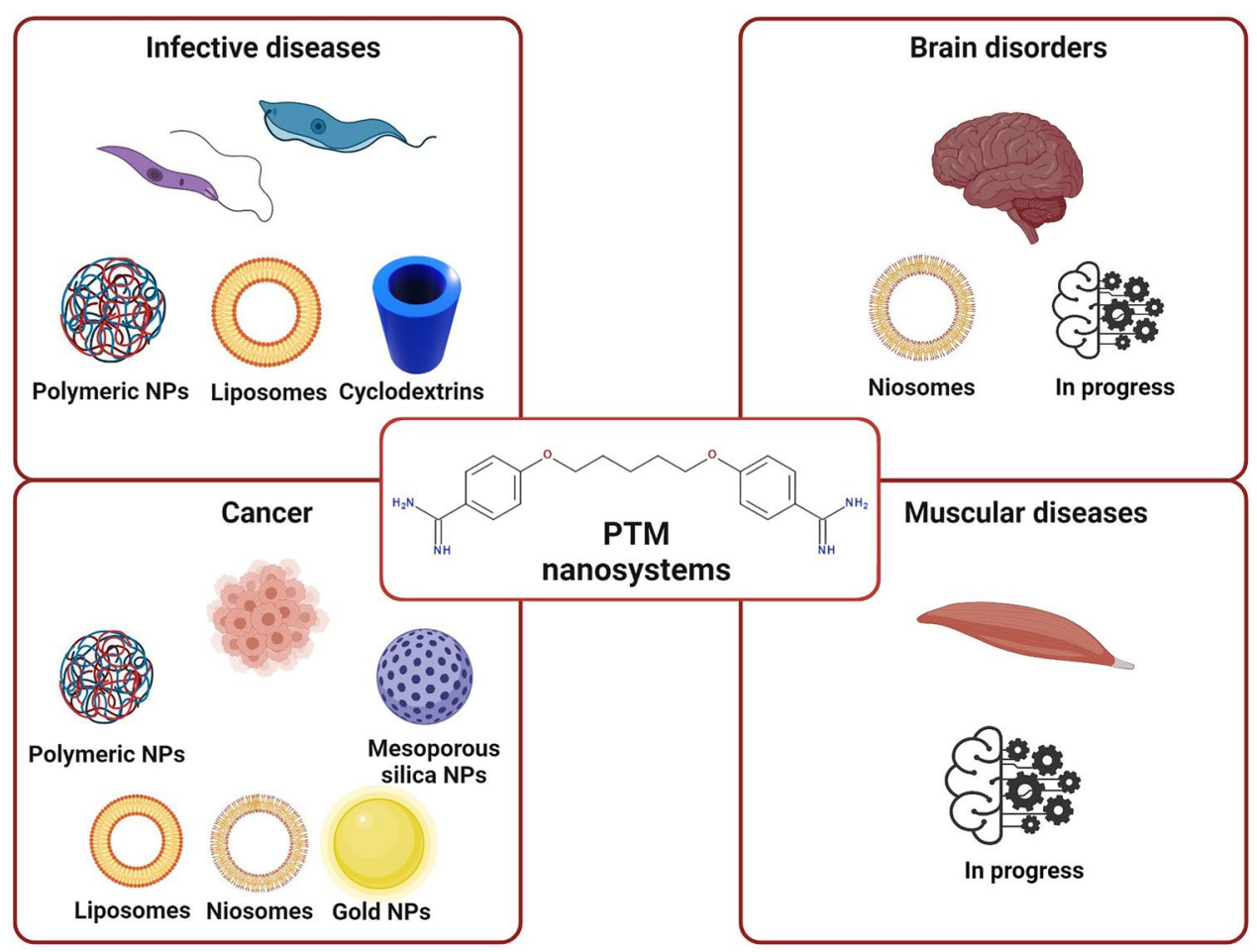

had a $\mathrm{pH}$-depend profile that increased in an acidic environment due to the chemical properties of PTM, which is advantageous for delivery to the parasitophorous vacuole of parasites ( $\mathrm{pH}$ 5). The in vitro tests on the PTM-loaded nanoparticles showed a reduction in inhibitory concentration, compared to the unloaded and untargeted formulations. The in vivo therapeutic efficacy was evaluated in a mouse model infected by Trypanosomiasis brucei in order to provide further confirmation of the in vitro results. Mice were treated by intraperitoneal injection (i.p.) with PTM-loaded targeted nanoparticles, and the complete resolution of infection was observed, unlike the group receiving the same nanoparticle without the nanobody surface functionalization. The possibility of the alternative internalization of an active agent may decrease spontaneous drug resistance that can limit or reduce the applicability of some antiprotozoal drugs [119].

Other nanomedicine approaches have focused on poly(D,L-lactide) (PLA) and PLGA polyesters as they are known to be biodegradable and biocompatible [121, 122]. Paul et al. have described the preparation, the physiochemical properties and the stability of PTM-loaded PLA nanoparticles. Loaded nanocarriers were obtained via the nanoprecipitation technique using a combination of phospholipids and a poloxamer, which influences the physiochemical characteristics of the nanosuspension. PTM loading improved when the lipid content was directly increased: indeed, varying the phospholipid concentration from 0.6 to $1.25 \%(\mathrm{w}: \mathrm{v})$, the highest drug loading (75.8\%) was obtained with the highest concentration of phospholipids (1.25\%). The formulation was stable over 9 months, in terms of its size and morphology [123, 124]. The biological evaluation of PTM-loaded PLA nanoparticles was performed by determining the $\mathrm{ED}_{50}$ against Leishmania infantum in male adult BALB/c mice by i.v. injection. A comparison between free PTM and loaded PTM showed the ability of PLA nanoparticles to induce a threefold increase in PTM activity $\left(\mathrm{ED}_{50}: 1.05 \mathrm{mg} / \mathrm{kg}\right.$ for PTM vs. $0.32 \mathrm{mg} / \mathrm{kg}$ for loaded nanoparticles) [125].

Due to the growing interest in polymeric nanoparticles for antiprotozoal drug delivery, PLGA nanocarriers have been widely described. In particular, investigations into PLGA nanoparticles as a potential tool to deliver PTM have been reported. Starting from the formulation of PLGA microparticles to improve the pharmacokinetics and pharmacodynamics drawbacks of PTM [126], several research groups have focused their attention on nano-structured PLGA drug delivery systems. Recently, Scala et al. have proposed the covalent linkage of PTM with a PEG-PLGA block copolymer and a hyaluronic acid backbone by click chemistry. They aimed to evaluate the activity of free PTM and PTM bioconjugates. Moreover, they compared the therapeutic effects of PTM-loaded PEG-PLGA-PTM nanoparticles. The anti-leishmanial activity of PTM bioconjugates and PTM nanoparticles was assessed in vitro against infected macrophages. PTM bioconjugate and PTM nanoparticles displayed an $\mathrm{IC}_{50} 3.6$ and 3.4 times lower than free PTM, respectively. In particular, the bioconjugate with hyaluronic acid was found to be the most active derivate, characterized by an $\mathrm{IC}_{50}$ value of $1.7 \mu \mathrm{M}$ compared 
to $7.5 \mu \mathrm{M}$ of free PTM, confirming the effectiveness of the hyaluronic acid targeting scaffold [127].

As has already been reported for polyacrylates, PLGA nanoparticles were loaded with PTM and surface-engineered to efficiently recognize the surface of the protozoan pathogen Trypanosoma brucei, in particular a hidden conserved epitope within the glycophosphatidylinositol (GPI) anchor of the VSG protein (Fig. 4). PEGylated PTM-loaded PLGA nanoparticles were prepared via the water-in-oil-in-water (w/o/w) double emulsion/solvent evaporation technique, followed by PLGA functionalization with PEG chains and NbAn33 nanobodies (both through the EDC/NHS approach) for protozoan-surface recognition. A monodispersed nanosuspension that was characterized by a $145 \mathrm{~nm}$ mean diameter and a negative zeta potential value, of around $-20 \mathrm{mV}$, was produced. In vitro studies highlighted the threefold increased efficacy of PTM-loaded PLGA nanocarriers. Moreover, the efficacy of the polymeric formulation increased fourfold again after surface functionalization by nanobodies, which underlines the importance of active targeting in enhancing cellular uptake in parasitic diseases. In vivo tests in an acute mouse model of African trypanosomiasis confirmed the urgent need for surface-nanobody conjugation. The infections of mice injected i.p. with the nanobody-targeted formulation were completely resolved at a tenfold lower dose. In vivo PTM activity was significantly optimized by PLGA encapsulation and, most of all, by surface functionalization, demonstrating that the trypanosome surface was an excellent therapeutic target [128].

PTM-loaded PLGA nanoparticles were developed, using the same preparation technique, for oral delivery in the treatment of Leishmania [129]. For the first time, the application of nanoparticles was devoted to the oral delivery of an antiprotozoal drug. The formulation of PTM-loaded PLGA nanoparticles included polyvinyl alcohol (PVA) as a stabilizer, which reduced the zeta potential value to around neutrality and gave a size of around $250 \mathrm{~nm}$. The in vitro release profile confirmed the data reported by Arias et al. which described an initial burst release followed by constant release over 25 days [128]. In this study, the evaluation of the possible oral delivery of PTM-loaded nanoparticles was innovative and highly interesting. In vivo tests performed in a murine visceral leishmaniasis model aimed to compare infection resolution via the oral and s.c. delivery of loaded nanoparticles. S.c. administration did not lead to significant reductions in spleen and liver weight, which is the major end point in infective-disease studies. Interestingly, a reduction in the parasite presence in the spleen occurred after oral administration, which demonstrated the enhanced PTM uptake that was achieved by the oral route [129].

An innovative approach has recently been proposed to understand the toxicity of PTM through the BBB in the treatment of African trypanosomiasis. Sanderson et al. have evaluated the complexation of PTM with Pluronic, a polymer that can act as a stabilizer to prevent aggregation, opsonization, and recognition by macrophages and thus increase drug half-life, but that can also assemble into micelles to encapsulate drugs. Although the study did not show the increased uptake of PTM by the brain, this is, nonetheless, a new formulation of PTM that has been proposed as an alternative approach to test the activity of PTM on an African trypanosomiasis model [54].

\section{Inclusion complexes}

Cyclodextrins (CD) are composed of 6, 7, or 8 glucopyranose units (named $\alpha-, \beta-$, and $\gamma-\mathrm{CD}$, respectively) linked by a glycosidic bond and organized in a truncated cone. Polar hydroxyl groups on the molecule's border confer water solubility, while the inner hydrophobic cavity allows a variety of drugs to be hosted, forming inclusion complexes. $\beta-C D$ are useful as they can improve the physico-chemical and biological properties of the included molecules, increasing tolerance and alleviating the drawbacks [130-133].

De Paula et al. have investigated the inclusion of PTM into the $\beta$-CD cavity, and then studied its activity when given via oral administration. First, $\beta$-CD that contained PTM ( $\beta$-CD:PTM) were prepared using a freeze-drying method and tested in vivo
Fig. 4 A Schema of the VSG coat on trypanosome surface, in which the NbAn33 nanobody recognizes a hidden conserved epitope within the GPI anchor. B Schema of a NbAn33-PTMPLGA nanoparticle. Reproduced with permission from [128]. Copyright Elsevier 2015

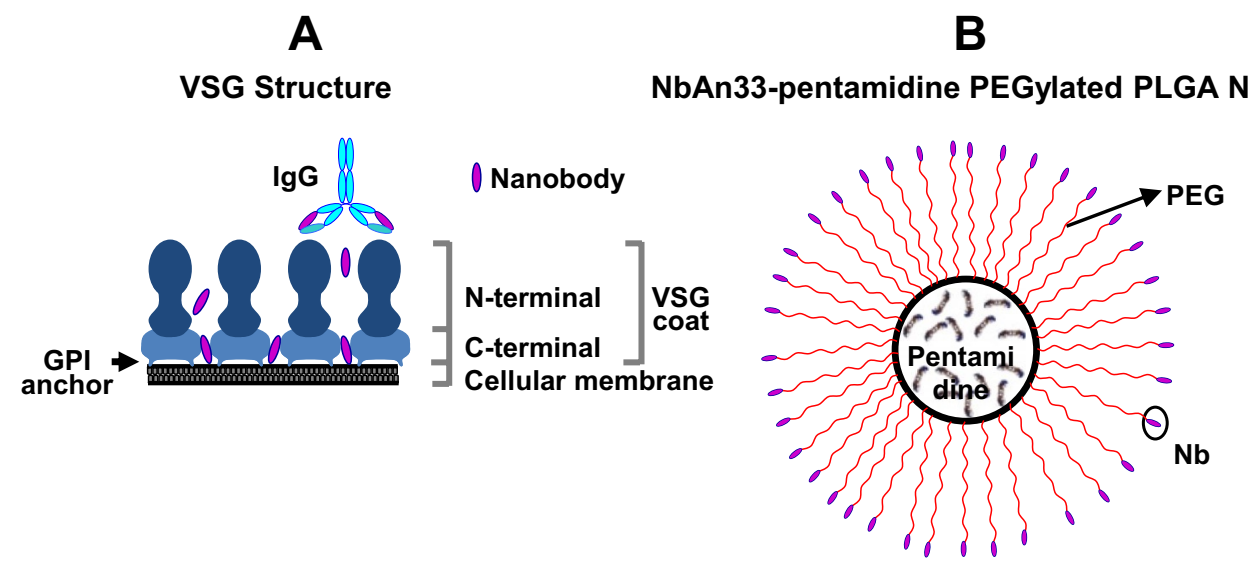


against Leishmania infantum chagasi parasites. Groups of mice were infected in the tail vein with promastigotes and treated with free PTM, $\beta$-CD:PTM (1:1), a saline solution, and Glucantime ${ }^{\circledR}$ (meglumine antimoniate, an approved antiprotozoal drug). No differences were found in the groups treated with free PTM and the control group, which was treated with the saline solution, in the liver and spleen. Orally administered $\beta$-CD:PTM and Glucantime ${ }^{\circledR}$ had similar efficacy, which was in contrast with the results obtained with orally administered PTM, which did not induce a significant reduction of the parasite burden. In addition, $\beta$-CD:PTM showed a greater reduction of parasitemia in the liver. The results demonstrated that $\beta$-CD:PTM are a promising alternative for the treatment of leishmaniasis [134].

\section{PTM for other therapeutic purposes}

As reported above, PTM has also been considered for possible clinical repositioning as an anti-Alzheimer's, anti-Parkinson's, and anticancer drug. PTM has been incorporated into different nanocarrier systems, whose composition and physico-chemical characteristics depend on both the administration route and physiopathological features, for each of these diseases (Table 2 and Fig. 3).

\section{Niosomes}

Besides liposomes, other nanoscale vesicles that contain aqueous cores have been used to deliver PTM, namely niosomes. Also known as non-ionic surfactant vesicles, niosomes are self-assembled vesicular nanocarriers formed of one or more layers of non-ionic surfactants and additives; niosomes can overcome some of the problems associated with liposomes, such as their low physical stability and high manufacturing costs [135].

PTM-loaded niosomes have been designed to reach the brain via intranasal administration, bypassing the BBB as a possible tool in brain disorders. Indeed, PTM inhibits S100 calcium-binding protein B (S100B) in glial cells through the blockage of the interaction between the S100B and p53 proteins [136]; PTM is able to exert anti-inflammatory and neuroprotective effects [137], as high expression levels of S100B have been shown to cause neuroinflammation and the progression of brain diseases [138, 139]. Nevertheless, PTM has a poor capacity to cross the BBB and reach the brain after intranasal administration [140]. In a first approach to the delivery of PTM to the brain, the drug was associated to niosomes for the treatment of Alzheimer's disease [141]. Commercial PTM isethionate was located in the bilayer, with an entrapment efficiency of about $10 \%$, using the thin film hydration method. To overcome the low drug availability that is caused by rapid mucus clearance in the nasal cavity, mucoadhesive properties were provided to PTMloaded niosomes by coating them with chitosan glutamate
(CG) thanks to the electrostatic interactions between positively charged chitosan and the negatively charged dicetyl phosphate on the niosome surface. The interaction with mucin was confirmed using dynamic light scattering and fluorescence turbidity measurements for both uncoated and CG-coated niosomes, and is probably due to a non-specific mucin interaction. Nevertheless, CG can also act as a stabilizer and a penetration enhancer by widening the tight junctions between mucosal epithelial cells [142].

Further studies with PTM-niosomes were conducted in a Parkinson's disease murine model. In particular, chitosan-coated niosomes that contained PTM (entrapment efficiency of about $25 \%$ ) were administered daily via the intranasal route in subchronic (1-methyl-4-phenyl-1,2,3,6tetrahydropyridine) hydrochloride (MPTP)-intoxicated mice. The results showed that PTM-niosomes allowed $35-40 \%$ of the drug to be delivered into the brain. Moreover, the intranasal administration of PTM-loaded niosomes leads to an improvement of all the disease hallmarks and a significant reduction in neuroinflammation markers in mice, leading to a significant improvement in parkinsonian motor dysfunctions [143].

The S100B protein is also constitutionally expressed by enteric glial cells in the enteric nervous system; when it is overexpressed, it has a role in the perpetuation of a tumor-promoting microenvironment, driving the progression from chronic intestinal inflammation to colonic neoplastic lesions [144]. Thus, in order to evaluate PTM as a potential anticancer drug, the expression levels of the S100B and p53 proteins were quantified in human biopsies that were derived from controls, peritumoral tissues, ulcerative colitis, and colon cancer patients, at baseline and after the addition of PTM-loaded niosomes. The results showed that encapsulated PTM inhibits S100B activity and rescues p53 expression, leading to pro-apoptotic control in colon cancer. Moreover, the combination of PTM with gastro-resistant and bioadhesive niosomes will allow the drug to increase colonic bioavailability after oral administration [145].

\section{Polymer nanoparticles and liposomes}

In other approaches, the design of biocompatible PTMloaded polymer nanocarriers has taken advantage of the drug's chemical structure, as PTM has two terminal amidine groups that are protonated in a wide $\mathrm{pH}$ range, including physiological/neutral conditions [146]. For example, PTM has been combined with nanocomplexes, made of the polymers hyaluronic acid and polyarginine, thanks to the electrostatic interactions between the anionic polysaccharide and the cationic drug (Fig. 5) [147]. In these structures, polyarginine was used to crosslink hyaluronic acid and form nanoparticles.

The measurements of the counterion isethionate released from the drug during nanoparticle formation, using ion 
Fig. 5 Formation of PTMloaded nanoparticles by polyelectrolyte association. Reproduced with permission from [147]. Copyright Elsevier 2019

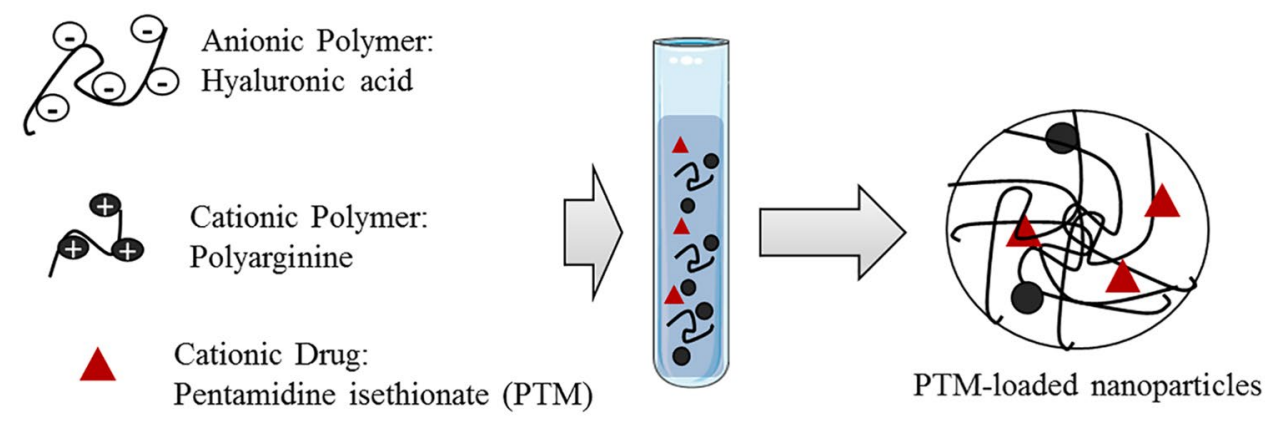

exchange chromatography, showed a high drug encapsulation efficiency $(80 \%)$. A comparison of the in vitro anticancer activity of free and encapsulated PTM in human lung (A549) and breast (MDA-MB-231) cancer cell lines suggested that the polyelectrolyte complexes allow enhanced cell internalization of the cationic drug to occur, with this probably being due to its more hydrophobic character after complexation, and increased cytotoxicity was thus observed. Moreover, both cell lines express CD44 receptors that specifically recognize hyaluronic acid. The polyelectrolyte complexes can therefore be selectively targeted towards these cancer cells through the interaction with these receptors [147].

Other biocompatible polymers have been used to deliver PTM to cancer cells via electrostatic interactions. In particular, negatively charged PLGA (with and without PEG) has been used to load the PTM free base (obtained from the commercial PTM isethionate to increase the drug lipophilicity) via the nanoprecipitation technique. In the same study, PTM was encapsulated into liposomes, as the free base or with different counterions, namely PTM citrate and PTM sulfate, for comparison. PTM base-containing liposomes were prepared using the thin lipid film hydration method by mixing phospholipids, cholesterol, and the PTM base in the organic phase, while PTM citrate and PTM sulfate were encapsulated into liposomes with a transmembrane citrate or sulfate gradient, starting from PTM isethionate in the external liposomal phase. This approach increased the encapsulation efficiency from $20 \%$ for the PTM base to $30 \%$ for PTM citrate and $45 \%$ for PTM sulfate. In PLGA nanoparticles, the PTM free base was almost totally incorporated (about 90\%) thanks to the lipophilic and ionic interactions between PLGA and PTM. Drug release was faster for polymer nanoparticles than liposomes and, as a consequence, the cytotoxicity (evaluated in the A2780 human ovarian carcinoma cell line) was different and tunable according to the nanocarrier and the PTM form [148].

Moving on to liposomes in the anticancer field, other liposomal PTM formulations have been prepared using saturated/ unsaturated phospholipids of different chain lengths and cholesterol content, with or without PEG on the outer surface. In this study, PTM isethionate was incorporated, using the thin lipid film hydration method, via its addition to the aqueous phase in the hydration procedure. The liposome composition greatly influenced the particle mean size, zeta potential, and encapsulation efficiency, which was in the $1-13 \%$ range. The pharmacokinetics profile of PTM, in five liposome formulations administered in non-tumor-bearing mice, showed that both the clearance and volume of distribution of PTM were significantly lower when administered in liposomes, compared to the free drug. PTM biodistribution and tumor accumulation after i.v. administration were evaluated in tumorbearing mice (colorectal, lung, ovarian, and breast cancer). The results showed that liposomal PTM increased tumor drug accumulation and lowered drug exposure to vulnerable tissues, such as the kidneys, compared to the free drug [149].

\section{Inorganic nanoparticles}

Inorganic nanocarriers have also been used, with functionalized mesoporous silica nanoparticles (MSN) having been proposed for PTM delivery. MSN are versatile and stable materials with a mesoporous structure, a high specific surface area, and a huge, tunable pore volume that can accommodate large amounts of bioactive compounds. Both the external and inner surfaces can be functionalized with linkers, and this functionalization can affect therapeutic agent loading and release profiles and greatly influence MSN fate in biological fluids [150]. In particular, the encapsulation of PTM isethionate and the PTM free base into bare (MSN-OH), aminopropyl (MSN-NH $\mathrm{N}_{2}$, cyanopropyl (MSN-CN), and carboxypropyl (MSN-COOH)-functionalized MSN has been investigated. PTM isethionate was not incorporated into any MSN, while the PTM free base displayed significant drug loading with MSN-OH and MSN-COOH thanks to the electrostatic interactions. MSN-CN showed slower drug loading, while the adsorption capacity of $\mathrm{MSN}-\mathrm{NH}_{2}$ was found to be negligible. The presence of different functional groups also influenced the release of the drug: MSN-COOH showed higher retention than MSN-OH, indicating that the hydrophobic interactions of the drug with the grafted propyl chains had a significant impact on the stabilization of the host-guest complex [151]. This work allowed the authors to select MSN-COOH as the most promising functionalized MSN to be further used as 


\section{Nanocarriers}

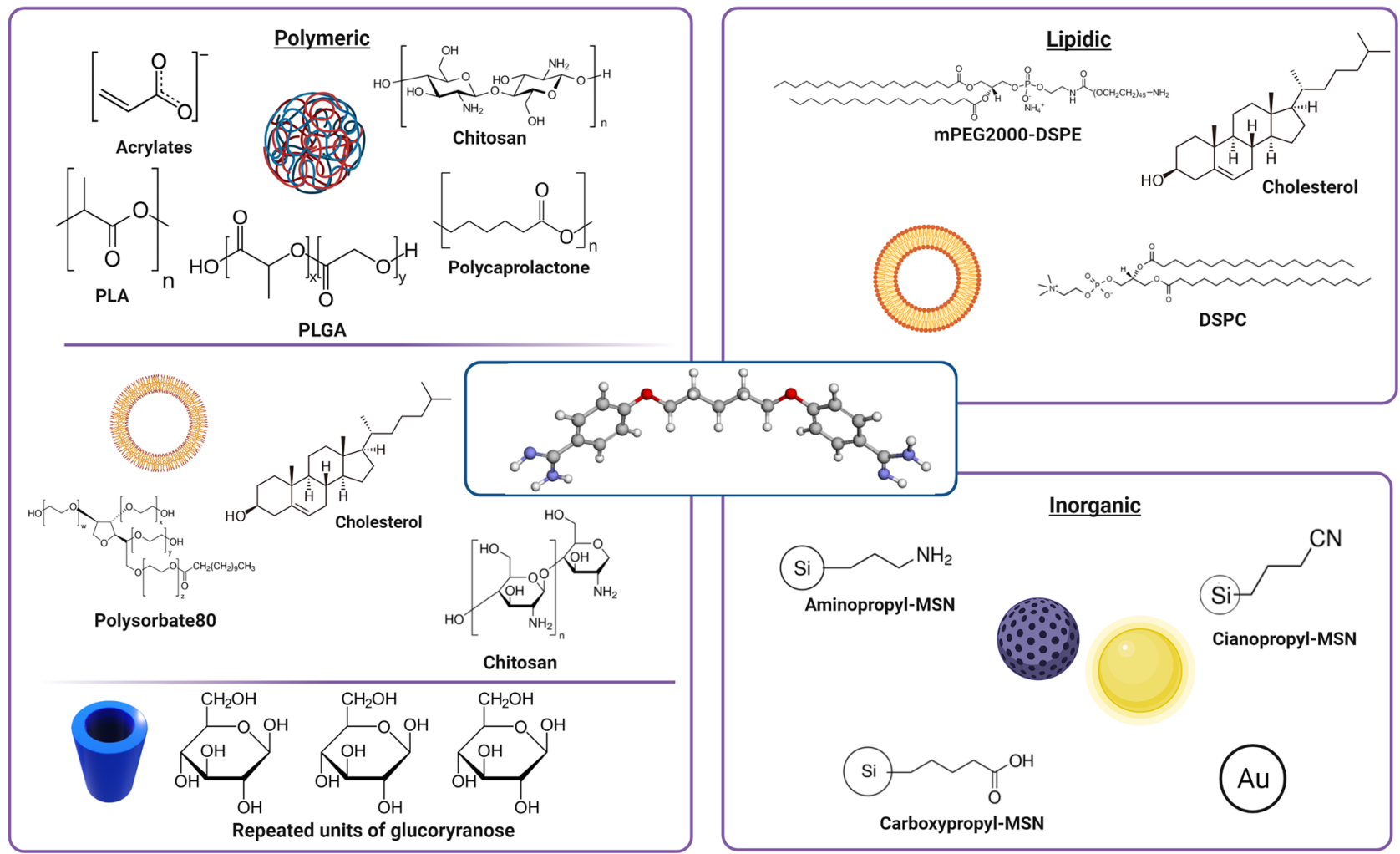

Fig. 6 Summary of PTM-loaded nanocarriers as a function of their chemical composition (created with BioRender.com)

drug delivery system that could be proposed for PTM delivery towards either cancer or muscle cells [152].

PTM has also been considered for use in combination with PEG-stabilized gold nanoparticles (AuNP) to enhance the effect of radiotherapy, in two triple-negative breast cancer cell lines, by targeting multiple pathways of radiosensitization. Although the loading of PTM onto AuNP was not the goal of the study, the authors evaluated the effect of AuNP as a single agent, in combination with PTM and after the pre-adsorption of the drug onto the nanoparticle surface to elucidate the underlying mechanisms of radiosensitization by the AuNP-PTM combination. The results showed that PTM enhances the radiosensitization effect of PEG-AuNP by exerting a dual action: by inhibiting radiation-induced DNA repair and increasing the cellular uptake of PEG-AuNP after surface adsorption, causing a change in the particle surface charge [153].

\section{Conclusion}

PTM is an old, FDA- and EMA-approved drug whose repurposing and delivery via nanocarriers of different composition have been extensively investigated (Fig. 6). Indeed, the interest in PTM is due to its well-known toxicology profile and multifactorial mechanism of action, although the latter has not yet been fully understood. PTM is appealing in terms of the design of nano-sized carriers as it is a small molecule whose physico-chemical characteristics (e.g., solubility in water and organic solvents) can be changed according to the PTM form (salt or free base) and the counterion in the salts. Moreover, PTM is positively charged at physiological $\mathrm{pH}$, thus allowing both electrostatic and lipophilic interactions with nanocarrier components that can, in this way, reduce the positive charge of the drug and increase its passage through the cell membrane. The incorporation into nanocarriers may also modify the toxicological profile of PTM and/or allow the drug to be actively targeted towards the target site, lowering the administered dose. Finally, the reported variety of nanocarriers that are suitable for PTM delivery facilitate the tuning of drug encapsulation efficiency and release rate as a function of the disease and patient features. This aspect is of a crucial importance, as it has been demonstrated that PTM could be repurposed for pathologies other than infectious ones, especially rare muscular diseases, and this aspect justifies a renewed interest in PTM and further multidisciplinary efforts for investigations in this field.

However, several papers on PTM-loaded nanocarriers reported in the present review describe only preliminary in vitro results or even just formulative studies. Therefore, 
a deeper analysis on the in vivo behavior of PTM-loaded nanocarriers is needed, particularly using models with animals infected with parasites or affected by the diseases for which PTM has been repurposed.

In conlusion, it is worth adding that the combination of PTM and nanocarriers implies also well-known critical features, especially in terms of industrial feasibility, as the system complexity increases. Indeed, the encapsulation of PTM would involve higher costs if compared to the production of the free drug. Furthermore, problems concerning the scalability, reproducibility (in terms of physico-chemical characteristics, such as mean size, zeta potential, drug loading), and compliance to regulatory standards can hamper its use in the clinic. All these issues have to be taken into account and evaluated as a function of the repurposed application.

Acknowledgements The authors thank Dr. Dale James Matthew Lawson for language editing.

Author contribution All authors contributed to the writing of this manuscript.

\section{Availability of data and materials Not applicable.}

\section{Declarations}

Ethics approval and consent to participate Not applicable.

Consent for publication All authors approved the version to be published.

Competing interests The authors declare no competing interests.

Open Access This article is licensed under a Creative Commons Attribution 4.0 International License, which permits use, sharing, adaptation, distribution and reproduction in any medium or format, as long as you give appropriate credit to the original author(s) and the source, provide a link to the Creative Commons licence, and indicate if changes were made. The images or other third party material in this article are included in the article's Creative Commons licence, unless indicated otherwise in a credit line to the material. If material is not included in the article's Creative Commons licence and your intended use is not permitted by statutory regulation or exceeds the permitted use, you will need to obtain permission directly from the copyright holder. To view a copy of this licence, visit http://creativecommons.org/licenses/by/4.0/.

\section{References}

1. Shi J, Votruba AR, Farokhzad OC, Langer R. Nanotechnology in drug delivery and tissue engineering: from discovery to applications. Nano Lett. 2010;10:3223-30.

2. Nicolas J, Mura S, Brambilla D, Mackiewicz N, Couvreur P. Design, functionalization strategies and biomedical applications of targeted biodegradable/biocompatible polymer-based nanocarriers for drug delivery. Chem Soc Rev. 2013;42:1147-235.
3. Kim KS, Suzuki K, Cho H, Youn YS, Bae YH. Oral nanoparticles exhibit specific high-efficiency intestinal uptake and lymphatic transport. ACS Nano. 2018;12:8893-900.

4. van der Meel R, Sulheim E, Shi Y, Kiessling F, Mulder WJM, Lammers T. Smart cancer nanomedicine. Nat Nanotechnol. 2019;14:1007-17.

5. Babazadeh A, Mohammadi Vahed F, Jafari SM. Nanocarrier-mediated brain delivery of bioactives for treatment/prevention of neurodegenerative diseases. J Control Release. 2020;321:211-221.

6. Hanif S, Muhammad P, Chesworth R, Rehman FU, Qian RJ, Zheng M, Shi BY. Nanomedicine-based immunotherapy for central nervous system disorders. Acta Pharmacol Sin. 2020;41:936-53.

7. Tavakol S, Zahmatkeshan M, Mohammadinejad R, Mehrzadi S, Joghataei MT, Alavijeh MS, Seifalian A. The role of nanotechnology in current COVID-19 outbreak. Heliyon. 2021;7:e68841.

8. Tan YF, Lao LL, Xiong GM, Venkatraman S. Controlledrelease nanotherapeutics: state of translation. J Control Release. 2018;284:39-48.

9. Arpicco S, Battaglia L, Brusa P, Cavalli R, Chirio D, Dosio F, Gallarate M, Milla P, Peira E, Rocco F, Sapino S, Stella B, Ugazio E, Ceruti M. Recent studies on the delivery of hydrophilic drugs in nanoparticulate systems. Journal of Drug Delivery Science and Technology. 2016;32:298-312.

10. FDA Abbreviated New Drug Application: 206666 pentamidine isethionate.

11. List of EU nationally authorized medicinal products with active substance pentamidine. Procedure No.: PSUSA/00002338/201706.

12. Sands M, Michael AK, Brown RB. Pentamidine: a review. Rev Infect Dis. 1985;7:625-34.

13. Burri C. Chemotherapy against human African trypanosomiasis: is there a road to success? Parasitology. 2010;137:1987-94.

14. Wishart DS, Feunang YD, Guo AC, Lo EJ, Marcu A, Grant JR, Sajed T, Johnson D, Li C, Sayeeda Z, Assempour N, Iynkkaran I, Liu Y, MacIejewski A, Gale N, Wilson A, Chin L, Cummings R, Le D, Pon A, Knox C, Wilson M. DrugBank 5.0: A major update to the DrugBank database for 2018. Nucleic Acids Res. 2018;46:D1074-D1082.

15. Fairlamb AH. Chemotherapy of human African trypanosomiasis: current and future prospects. Trends Parasitol. 2003;19:488-94.

16. Clement B, Burenheide A, Rieckert W, Schwarz J. Diacetyldiamidoximeester of pentamidine, a prodrug for treatment of protozoal diseases: synthesis, in vitro and in vivo biotransformation. ChemMedChem. 2006;1:1260-7.

17. Girard PM, Brun-Pascaud M, Farinotti R, Tamisier L, Kernbaum $\mathrm{S}$. Pentamidine aerosol in prophylaxis and treatment of murine Pneumocystis carinii pneumonia. Antimicrob Agents Chemother. 1987;31:978-81.

18. Pentam (pentamidine isethionate i.v., i.m. injection) [Product Information]. APP Pharmaceuticals, LLC, Schaumburg, IL, 2008.

19. NebuPent (pentamidine isethionate oral inhalation) [Product Information]. APP Pharmaceuticals, LLC, Schaumburg, IL, 2011.

20. Jamshaid H, Din FU, Khan GM. Nanotechnology based solutions for anti-leishmanial impediments: a detailed insight. J Nanobiotechnology. 2021;19:106.

21. Porcheddu A, Giacomelli G, De Luca L. New pentamidine analogues in medicinal chemistry. Curr Med Chem. 2012;19:5819-36.

22. Soeiro MN, Werbovetz K, Boykin DW, Wilson WD, Wang MZ, Hemphill A. Novel amidines and analogues as promising agents against intracellular parasites: a systematic review. Parasitology. 2013;140:929-51. 
23. Mandal TK. Evaluation of a novel phase separation technique for the encapsulation of water-soluble drugs in biodegradable polymer. Drug Dev Ind Pharm. 1998;24:623-9.

24. Mandal TK. Effect of solvent on the characteristics of pentamidine loaded microcapsule. J Biomater Sci Polym Ed. 1999;10:1-17.

25. Mandal TK, Bostanian LA, Graves RA, Chapman SR, Idodo TU. Porous biodegradable microparticles for delivery of pentamidine. Eur J Pharm Biopharm. 2001;52:91-6.

26. Mandal TK, Bostanian LA, Graves RA, Chapman SR. Poly(D, L-lactide-co-glycolide) encapsulated poly(vinyl alcohol) hydrogel as a drug delivery system. Pharm Res. 2002;19:1713-9.

27. Bray PG, Barrett MP, Ward SA, de Koning HP. Pentamidine uptake and resistance in pathogenic protozoa: past, present and future. Trends Parasitol. 2003;19:232-9.

28. Huang YS, Yang JJ, Lee NY, Chen GJ, Ko WC, Sun HY, Hung CC. Treatment of Pneumocystis jirovecii pneumonia in HIV-infected patients: a review. Expert Rev Anti Infect Ther. 2017;15:873-92.

29. Soeiro MN, De Souza EM, Stephens CE, Boykin DW. Aromatic diamidines as antiparasitic agents. Expert Opin Investig Drugs. 2005; 14:957-72.

30. Werbovetz K. Diamidines as antitrypanosomal, antileishmanial and antimalarial agents. Curr Opin Investig Drugs. 2006;7:147-57.

31. Alvar J, Velez ID, Bern C, Herrero M, Desjeux P, Cano J, Jannin J, den Boer M, W.H.O.L.C. Team. Leishmaniasis worldwide and global estimates of its incidence. PLoS One. 2012;7:e35671.

32. World Health Organization, Health Topics, Leishmaniasis. https://www.who.int/westernpacific/health-topics/leishmaniasis. Accessed 15 Mar 2021.

33. Burza S, Croft SL, Boelaert M. Leishmaniasis. Lancet. 2018;392:951-70.

34. Reithinger R, Dujardin JC, Louzir H, Pirmez C, Alexander B, Brooker S. Cutaneous leishmaniasis. Lancet Infect Dis. 2007;7:581-96.

35. Mann S, Frasca K, Scherrer S, Henao-Martinez AF, Newman S, Ramanan P, Suarez JA. A review of leishmaniasis: current knowledge and future directions. Curr Trop Med Rep. 2021;1-12.

36. Chawla B, Madhubala R. Drug targets in Leishmania. J Parasit Dis. 2010;34:1-13.

37. Stone NR, Bicanic T, Salim R, Hope W. Liposomal amphotericin B (AmBisome $\left({ }^{\circledR}\right)$ ): a review of the pharmacokinetics, pharmacodynamics, clinical experience and future directions. Drugs. 2016;76:485-500.

38. Sundar S, Jha TK, Thakur CP, Sinha PK, Bhattacharya SK. Injectable paromomycin for visceral leishmaniasis in India. $\mathrm{N}$ Engl J Med. 2007;356:2571-81.

39. Ponte-Sucre A, Gamarro F, Dujardin JC, Barrett MP, LopezVelez R, Garcia-Hernandez R, Pountain AW, Mwenechanya R, Papadopoulou B. Drug resistance and treatment failure in leishmaniasis: a 21st century challenge. PLoS Negl Trop Dis. 2017;11:e006052.

40. Bansal R, Sen SS, Muthuswami R, Madhubala R. Stigmasterol as a potential biomarker for amphotericin B resistance in Leishmania donovani. J Antimicrob Chemother. 2020;75:942-50.

41. Kennedy PG. Clinical features, diagnosis, and treatment of human African trypanosomiasis (sleeping sickness). Lancet Neurol. 2013;12:186-94.

42. Kennedy PGE, Rodgers J. Clinical and neuropathogenetic aspects of human African trypanosomiasis. Front Immunol. 2019;10:39.

43. World Health Organization, Fact sheets, Trypanosomiasis, human African (sleeping sickness). https://www.who.int/news-room/ fact-sheets/detail/trypanosomiasis-human-african-(sleepingsickness). Accessed 15 Mar 2021.
44. Dubois ME, Demick KP, Mansfield JM. Trypanosomes expressing a mosaic variant surface glycoprotein coat escape early detection by the immune system. Infect Immun. 2005;73:2690-7.

45. Brun R, Blum J, Chappuis F, Burri C. Human African trypanosomiasis. Lancet. 2010;375:148-59.

46. Bottieau E, Clerinx J. Human African trypanosomiasis: progress and stagnation. Infect Dis Clin North Am. 2019;33:61-77.

47. Buscher P, Cecchi G, Jamonneau V, Priotto G. Human African trypanosomiasis. Lancet. 2017;390:2397-409.

48. Arino T, Karakawa S, Ishiwata Y, Nagata M, Yasuhara M. Effect of cimetidine on pentamidine induced hyperglycemia in rats. Eur J Pharmacol. 2012;693:72-9.

49. Coyle P, Carr AD, Depczynski BB, Chisholm DJ. Diabetes mellitus associated with pentamidine use in HIV-infected patients. Med J Aust. 1996;165:587-8.

50. Kuryshev YA, Ficker E, Wang L, Hawryluk P, Dennis AT, Wible BA, Brown AM, Kang J, Chen XL, Sawamura K, Reynolds W, Rampe D. Pentamidine-induced long QT syndrome and block of hERG trafficking. J Pharmacol Exp Ther. 2005;312:316-23.

51. Antoniou T, Gough KA. Early-onset pentamidine-associated second-degree heart block and sinus bradycardia: case report and review of the literature. Pharmacotherapy. 2005;25:899-903.

52. Glikson M, Dresner-Feigin R, Pollack A, Wolf D, Galun E, Tur-Kaspa R. Pentamidine-induced cardiotoxicity. Isr J Med Sci. 1990;26:588-9.

53. de Menezes JP, Guedes CE, Petersen AL, Fraga DB, Veras PS. Advances in development of new treatment for leishmaniasis. Biomed Res Int. 2015;2015:815023.

54. Sanderson L, da Silva M, Sekhar GN, Brown RC, Burrell-Saward H, Fidanboylu M, Liu B, Dailey LA, Dreiss CA, Lorenz C, Christie M, Persaud SJ, Yardley V, Croft SL, Valero M, Thomas SA. Drug reformulation for a neglected disease. The NANOHAT project to develop a safer more effective sleeping sickness drug. PLoS Negl Trop Dis. 2021;15:e0009276.

55. Pelucio MT, Rothenhaus T, Smith M, Ward DJ. Fatal pancreatitis as a complication of therapy for HIV infection. J Emerg Med. 1995;13:633-7.

56. Prabhavalkar S, Masengu A, O'Rourke D, Shields J, Courtney A. Nebulized pentamidine-induced acute renal allograft dysfunction. Case Rep Transplant. 2013;2013:907593.

57. Huang TL, Mayence A, Vanden Eynde JJ. Some non-conventional biomolecular targets for diamidines. A short survey. Bioorg Med Chem. 2014;22:1983-1992.

58. Ortiz SC, Huang M, Hull CM. Spore germination as a target for antifungal therapeutics. Antimicrob Agents Chemother. 2019.

59. Vallieres C, Singh N, Alexander C, Avery SV. Repurposing nonantifungal approved drugs for synergistic targeting of fungal pathogens. ACS Infect Dis. 2020;6:2950-8.

60. Wu C, Xia L, Huang W, Xu Y, Gu Y, Liu C, Ji L, Li W, Wu Y, Zhou K, Feng X. Pentamidine sensitizes FDA-approved nonantibiotics for the inhibition of multidrug-resistant Gram-negative pathogens. Eur J Clin Microbiol Infect Dis. 2020;39:1771-9.

61. Nixon SA, Saez NJ, Herzig V, King GF, Kotze AC. The antitrypanosomal diarylamidines, diminazene and pentamidine, show anthelmintic activity against Haemonchus contortus in vitro. Vet Parasitol. 2019;270:40-6.

62. Walhart T, Isaacson-Wechsler E, Ang KH, Arkin M, Tugizov S, Palefsky JM. A cell-based Renilla luminescence reporter plasmid assay for high-throughput screening to identify novel FDAapproved drug inhibitors of HPV-16 infection. SLAS Discov. 2020;25:79-86.

63. Stead AM, Bray PG, Edwards IG, DeKoning HP, Elford BC, Stocks PA, Ward SA. Diamidine compounds: selective uptake and targeting in Plasmodium falciparum. Mol Pharmacol. 2001;59:1298-306. 
64. Tomar PPS, Krugliak M, Arkin IT. Blockers of the SARS-CoV-2 3a channel identified by targeted drug repurposing. Viruses. 2021;13.

65. Franco J, Scarone L, Comini MA. Chapter Three - Drugs and drug resistance in African and American trypanosomiasis. In: Botta M editor. Annual reports in medicinal chemistry. Academic Press; 2018. p. 97-133.

66. Reynolds IJ, Aizenman E. Pentamidine is an N-methyl-D-aspartate receptor antagonist and is neuroprotective in vitro. J Neurosci. 1992;12:970-5.

67. Block F, Schmitt T, Schwarz M. Pentamidine, an inhibitor of spinal flexor reflexes in rats, is a potent $\mathrm{N}$-methyl-D-aspartate (NMDA) antagonist in vivo. Neurosci Lett. 1993;155:208-11.

68. Kitamura Y, Arima T, Imaizumi R, Sato T, Nomura Y. Inhibition of constitutive nitric oxide synthase in the brain by pentamidine, a calmodulin antagonist. Eur J Pharmacol. 1995;289:299-304.

69. Sun T, Zhang Y. Pentamidine binds to tRNA through non-specific hydrophobic interactions and inhibits aminoacylation and translation. Nucleic Acids Res. 2008;36:1654-64.

70. Pathak MK, Dhawan D, Lindner DJ, Borden EC, Farver C, Yi T. Pentamidine is an inhibitor of PRL phosphatases with anticancer activity. Mol Cancer Ther. 2002;1:1255-64.

71. Chow TY, Alaoui-Jamali MA, Yeh C, Yuen L, Griller D. The DNA double-stranded break repair protein endo-exonuclease as a therapeutic target for cancer. Mol Cancer Ther. 2004;3:911-9.

72. Lee MS, Johansen L, Zhang Y, Wilson A, Keegan M, Avery W, Elliott P, Borisy AA, Keith CT. The novel combination of chlorpromazine and pentamidine exerts synergistic antiproliferative effects through dual mitotic action. Cancer Res. 2007;67:11359-67.

73. Smith J, Stewart BJ, Glaysher S, Peregrin K, Knight LA, Weber DJ, Cree IA. The effect of pentamidine on melanoma ex vivo. Anticancer Drugs. 2010;21:181-5.

74. Jung HJ, Suh SI, Suh MH, Baek WK, Park JW. Pentamidine reduces expression of hypoxia-inducible factor-1alpha in DU145 and MDA-MB-231 cancer cells. Cancer Lett. 2011;303:39-46.

75. Qiu G, Jiang J, Liu XS. Pentamidine sensitizes chronic myelogenous leukemia K562 cells to TRAIL-induced apoptosis. Leuk Res. 2012;36:1417-21.

76. Zerbini LF, Bhasin MK, de Vasconcellos JF, Paccez JD, Gu X, Kung AL, Libermann TA. Computational repositioning and preclinical validation of pentamidine for renal cell cancer. Mol Cancer Ther. 2014;13:1929-41.

77. Rahman A, O'Sullivan P, Rozas I. Recent developments in compounds acting in the DNA minor groove. Medchemcomm. 2019; 10:26-40.

78. Liu L, Wang F, Tong Y, Li LF, Liu Y, Gao WQ. Pentamidine inhibits prostate cancer progression via selectively inducing mitochondrial DNA depletion and dysfunction. Cell Prolif. 2020:53; 12718 .

79. Andreana I, Repellin M, Carton F, Kryza D, Briancon S, Chazaud B, Mounier R, Arpicco S, Malatesta M, Stella B, Lollo G. Nanomedicine for gene delivery and drug repurposing in the treatment of muscular dystrophies. Pharmaceutics. 2021;13.

80. Warf MB, Nakamori M, Matthys CM, Thornton CA, Berglund JA. Pentamidine reverses the splicing defects associated with myotonic dystrophy. Proc Natl Acad Sci U S A. 2009;106:18551-6.

81. Chakraborty M, Llamusi B, Artero R. Modeling of myotonic dystrophy cardiac phenotypes in Drosophila. Front Neurol. 2018;9:473.

82. Conte JE Jr, Upton RA, Phelps RT, Wofsy CB, Zurlinden E, Lin ET. Use of a specific and sensitive assay to determine pentamidine pharmacokinetics in patients with AIDS. J Infect Dis. 1986;154:923-9.
83. Conte JE Jr. Pharmacokinetics of intravenous pentamidine in patients with normal renal function or receiving hemodialysis. J Infect Dis. 1991;163:169-75.

84. Donnelly H, Bernard EM, Rothkotter H, Gold JW, Armstrong D. Distribution of pentamidine in patients with AIDS. J Infect Dis. 1988;157:985-9.

85. Thomas SH, Page CJ, Blower PJ, Chowienczyk P, Ward A, Kamali F, Bradbeer CS, Bateman NT, O’Doherty MJ. Disposition of intravenous 123iodopentamidine in man. Nucl Med Biol. 1997;24:327-32.

86. A safety study of pentamidine in patients with metastatic colon cancer undergoing standard chemotherapy as secondline and/or third-line treatment. https://ClinicalTrials.gov/ show/NCT00809796. Accessed 6 Jun 2021.

87. Using OCZ103-OS in patients with unresectable and locally recurrent or metastatic colorectal cancer undergoing standard chemotherapy. https://ClinicalTrials.gov/show/NCT01378143. Accessed 06 Jun 2021.

88. A safety study using pentamidine in patients with pancreatic cancer undergoing standard therapy, https://ClinicalTrials.gov/ show/NCT00810953. Accessed 6 Jun 2021.

89. An exploratory study of OCZ103-OS in combination with standard of care in stage IV non-small cell lung cancer (NSCLC) patients. https://ClinicalTrials.gov/show/NCT01844791. Accessed 6 Jun 2021.

90. M.S. Bilodeau M, Burak KW, Duan J, Ravenelle F, Colin P. Clinical evidence of hepatoselectivity of oral pentamidine (VLX103) in cirrhotic patients with early stage hepatocellular carcinoma. Hepatology. 2016;64:136-361.

91. M.S. Bilodeau M, Burak KW, Duan J, Ravenelle F, Colin P. Clinical safety and pharmacodynamics of VLX103, a new orally administered pentamidine formulation, in cirrhotic patients with early stage hepatocellular carcinoma. Hepatology. 2016;64:136-361.

92. Hypertrophic scar prevention by novel topical gel application. https://ClinicalTrials.gov/show/NCT03403621. Accessed 6 Jun 2021.

93. Miltefosine plus IL pentamidine for Bolivian CL. https://Clini calTrials.gov/show/NCT03445897. Accessed 6 Jun 2021.

94. Topical paromomycin for cutaneous leishmaniasis in Bolivia. https://ClinicalTrials.gov/show/NCT03096457. Accessed 6 Jun 2021.

95. Nafari A, Cheraghipour K, Sepahvand M, Shahrokhi G, Gabal E, Mahmoudvand H. Nanoparticles: new agents toward treatment of leishmaniasis, Parasite Epidemiol. Control. 2020;10:e0156-e0156.

96. Ortega V, Giorgio S, de Paula E. Liposomal formulations in the pharmacological treatment of leishmaniasis: a review. J Liposome Res. 2017;27:234-48.

97. de Almeida L, Terumi Fujimura A, Del Cistia ML, Fonseca-Santos B, Braga Imamura K, Michels PAM, Chorilli M, Graminha MAS. Nanotechnological strategies for treatment of leishmaniasis--a review. J Biomed Nanotechnol. 2017;13:117-133.

98. Tosyali OA, Allahverdiyev A, Bagirova M, Abamor ES, Aydogdu M, Dinparvar S, Acar T, Mustafaeva Z, Derman S. Nano-codelivery of lipophosphoglycan with soluble and autoclaved leishmania antigens into PLGA nanoparticles: evaluation of in vitro and in vivo immunostimulatory effects against visceral leishmaniasis. Mater Sci Eng C Mater Biol Appl. 2021;120:111684.

99. Borborema SET, Osso Jr JA, Tempone AG, de Andrade Jr HF, do Nascimento N. Pharmacokinetic of meglumine antimoniate encapsulated in phosphatidylserine-liposomes in mice model: a candidate formulation for visceral leishmaniasis. Biomed Pharmacother. 2018;103:1609-1616.

100. Kimani NM, Backhaus S, Matasyoh JC, Kaiser M, Herrmann FC, Schmidt TJ, Langer K. Preparation of sesquiterpene 
lactone-loaded PLA nanoparticles and evaluation of their antitrypanosomal activity. Molecules. 2019;24.

101. Pattni BS, Chupin VV, Torchilin VP. New developments in liposomal drug delivery. Chem Rev. 2015;115:10938-66.

102. Allen TM, Cullis PR. Liposomal drug delivery systems: from concept to clinical applications. Adv Drug Deliv Rev. 2013;65:36-48

103. Jain K, Jain NK. Novel therapeutic strategies for treatment of visceral leishmaniasis. Drug Discov Today. 2013;18:1272-81.

104. Das N, Mahato SB, Naskar K, Ghosh DK, Basu MK. Targeting of urea stibamine encapsulated in liposomes to reticuloendothelial system for the treatment of experimental leishmaniasis. Biochem Med Metab Biol. 1990;43:133-9.

105. Banerjee G, Nandi G, Mahato SB, Pakrashi A, Basu MK. Drug delivery system: targeting of pentamidines to specific sites using sugar grafted liposomes. J Antimicrob Chemother. 1996;38:145-50.

106. Siddiqui R, Syed A, Tomas S, Prieto-Garcia J, Khan NA. Effect of free versus liposomal-complexed pentamidine isethionate on biological characteristics of Acanthamoeba castellanii in vitro. $\mathbf{J}$ Med Microbiol. 2009;58:327-30.

107. Nguyen NB, Chen CH, Zhang Y, Zhao P, Wu BM, Ardehali R. Harnessing the versatility of PLGA nanoparticles for targeted Cre-mediated recombination. Nanomedicine. 2019;19:106-14.

108. Kefayat A, Vaezifar S. Biodegradable PLGA implants containing doxorubicin-loaded chitosan nanoparticles for treatment of breast tumor-bearing mice. Int J Biol Macromol. 2019;136:48-56.

109. Bruni N, Stella B, Giraudo L, Della Pepa C, Gastaldi D, Dosio F. Nanostructured delivery systems with improved leishmanicidal activity: a critical revie. Int J Nanomedicine. 2017;12:5289-5311.

110. Gaspar R, Opperdoes FR, Preat V, Roland M. Drug targeting with polyalkylcyanoacrylate nanoparticles: in vitro activity of primaquine-loaded nanoparticles against intracellular Leishmania donovani. Ann Trop Med Parasitol. 1992;86:41-9.

111. Deniau M, Durand R, Bories C, Paul M, Astier A, Couvreur P, Houin R. In vitro study of leishmanicidal agents with drug carriers. Ann Parasitol Hum Comp. 1993;68:34-7.

112. Paul M, Durand R, Boulard Y, Fusai T, Fernandez C, Rivollet D, Deniau M, Astier A. Physicochemical characteristics of pentamidine-loaded polymethacrylate nanoparticles: implication in the intracellular drug release in Leishmania major infected mice. J Drug Target. 1998;5:481-90.

113. Fusai T, Deniau M, Durand R, Bories C, Paul M, Rivollet D, Astier A, Houin R. Action of pentamidine-bound nanoparticles against Leishmania on an in vivo model. Parasite. 1994;1:319-24.

114. Fusai T, Boulard Y, Durand R, Paul M, Bories C, Rivollet D, Astier A, Houin R, Deniau M. Ultrastructural changes in parasites induced by nanoparticle-bound pentamidine in a Leishmania major/mouse model. Parasite. 1997;4:133-9.

115. Durand R, Paul M, Rivollet D, Houin R, Astier A, Deniau M. Activity of pentamidine-loaded methacrylate nanoparticles against Leishmania infantum in a mouse model. Int J Parasitol. 1997;27:1361-7.

116. Omarch G, Kippie Y, Mentor S, Ebrahim N, Fisher D, Murilla $\mathrm{G}$, Swai H, Dube A. Comparative in vitro transportation of pentamidine across the blood-brain barrier using polycaprolactone nanoparticles and phosphatidylcholine liposomes, Artif Cells Nanomed. Biotechnol. 2019;47:1428-36.

117. Maran N, Gomes PS, Freire-de-Lima L, Freitas EO, Freirede-Lima CG, Morrot A. Host resistance to visceral leishmaniasis: prevalence and prevention. Expert Rev Anti Infect Ther. 2016;14:435-42.
118. Onyilagha C, Uzonna JE. Host immune responses and immune evasion strategies in African trypanosomiasis. Front Immunol. 2019;10:2738.

119. Unciti-Broceta JD, Arias JL, Maceira J, Soriano M, Ortiz-Gonzalez M, Hernandez-Quero J, Munoz-Torres M, de Koning HP, Magez $\mathrm{S}$, Garcia-Salcedo JA. Specific cell targeting therapy bypasses drug resistance mechanisms in African trypanosomiasis. PLoS Pathog. 2015;11:e1004942.

120. Stijlemans B, Conrath K, Cortez-Retamozo V, Van Xong H, Wyns L, Senter P, Revets H, De Baetselier P, Muyldermans S, Magez S. Efficient targeting of conserved cryptic epitopes of infectious agents by single domain antibodies. African trypanosomes as paradigm, J Biol Chem. 2004;279:1256-61.

121. Makadia HK, Siegel SJ. Poly Lactic-co-glycolic acid (PLGA) as biodegradable controlled drug delivery carrier. Polymers (Basel). 2011;3:1377-97.

122. Danhier F, Ansorena E, Silva JM, Coco R, Le Breton A, Preat V. PLGA-based nanoparticles: an overview of biomedical applications. J Control Release. 2012;161:505-22.

123. Paul M, Fessi H, Laatiris A, Boulard Y, Durand R, Deniau M, Astier A. Pentamidine-loaded poly(d, l-lactide) nanoparticles: physicochemical properties and stability work. Int J Pharm. 1997;159:223-32.

124. Paul M, Laatiris A, Fessi H, Dufeu B, Durand R, Deniau M, Astier A. Pentamidine-loaded poly(D, L-lactide) nanoparticles: adsorption and drug release. Drug Dev Res. 1998;43:98-104.

125. Durand R, Paul M, Rivollet D, Fessi H, Houin R, Astier A, Deniau M. Activity of pentamidine-loaded poly (D, L-lactide) nanoparticles against Leishmania infantum in a murine model. Parasite. 1997;4:331-6.

126. Graves RA, Pamujula S, Moiseyev R, Freeman T, Bostanian LA, Mandal TK. Effect of different ratios of high and low molecular weight PLGA blend on the characteristics of pentamidine microcapsules. Int J Pharm. 2004;270:251-62.

127. Scala A, Piperno A, Micale N, Mineo PG, Abbadessa A, Risoluti R, Castelli G, Bruno F, Vitale F, Cascio A, Grassi G. "Click" on PLGA-PEG and hyaluronic acid: gaining access to anti-leishmanial pentamidine bioconjugates. J Biomed Mater Res B Appl Biomater. 2018;106:2778-85.

128. Arias JL, Unciti-Broceta JD, Maceira J, Del Castillo T, HernándezQuero J, Magez S, Soriano M, García-Salcedo JA. Nanobody conjugated PLGA nanoparticles for active targeting of African Trypanosomiasis. J Control Release. 2015;197:190-8.

129. Valle IV, Machado ME, Araujo C, da Cunha-Junior EF, da Silva Pacheco J, Torres-Santos EC, da Silva L, Cabral LM, do Carmo FA, Sathler PC. Oral pentamidine-loaded poly(d,1-lactic-coglycolic) acid nanoparticles: an alternative approach for leishmaniasis treatment. Nanotechnology 2019:30;455102.

130. Brewster ME, Loftsson T. Cyclodextrins as pharmaceutical solubilizers. Adv Drug Deliv Rev. 2007;59:645-66.

131. Loftsson T, Hreinsdottir D, Masson M. Evaluation of cyclodextrin solubilization of drugs. Int J Pharm. 2005;302:18-28.

132. Carrier RL, Miller LA, Ahmed I. The utility of cyclodextrins for enhancing oral bioavailability. J Control Release. 2007;123:78-99.

133. De Sousa FB, Lima AC, Denadai AM, Anconi CP, De Almeida WB, Novato WT, Dos Santos HF, Drum CL, Langer R, Sinisterra RD. Superstructure based on beta-CD self-assembly induced by a small guest molecule. Phys Chem Chem Phys. 2012;14:1934-44.

134. De Paula EE, De Sousa FB, Da Silva JC, Fernandes FR, Melo MN, Frezard F, Grazul RM, Sinisterra RD, Machado FC. Insights into the multi-equilibrium, superstructure system based on betacyclodextrin and a highly water soluble guest. Int J Pharm. 2012;439:207-15. 
135. Chen S, Hanning S, Falconer J, Locke M, Wen J. Recent advances in non-ionic surfactant vesicles (niosomes): fabrication, characterization, pharmaceutical and cosmetic applications. Eur J Pharm Biopharm. 2019;144:18-39.

136. Markowitz J, Chen I, Gitti R, Baldisseri DM, Pan Y, Udan R, Carrier F, MacKerell AD Jr, Weber DJ. Identification and characterization of small molecule inhibitors of the calcium-dependent S100B-p53 tumor suppressor interaction. J Med Chem. 2004;47:5085-93.

137. Cirillo C, Capoccia E, Iuvone T, Cuomo R, Sarnelli G, Steardo L, Esposito G. S100B unhibitor pentamidine attenuates reactive gliosis and reduces neuronal loss in a mouse model of Alzheimer's disease. Biomed Res Int. 2015;2015:508342.

138. Cristovao JS, Gomes CM. S100 proteins in Alzheimer's disease. Front Neurosci. 2019;13:463.

139. Liu J, Wang H, Zhang L, Xu Y, Deng W, Zhu H, Qin C. S100B transgenic mice develop features of Parkinson's disease. Arch Med Res. 2011;42:1-7.

140. Sekhar GN, Georgian AR, Sanderson L, Vizcay-Barrena G, Brown RC, Muresan P, Fleck RA, Thomas SA. Organic cation transporter 1 (OCT1) is involved in pentamidine transport at the human and mouse blood-brain barrier (BBB). PLoS One. 2017;12:e0173474.

141. Rinaldi F, Hanieh PN, Chan LKN, Angeloni L, Passeri D, Rossi M, Wang JT, Imbriano A, Carafa M, Marianecci C. Chitosan glutamate-coated niosomes: a proposal for nose-to-brain delivery. Pharmaceutics. 2018;10.

142. Kean T, Thanou M. Biodegradation, biodistribution and toxicity of chitosan. Adv Drug Deliv Rev. 2010;62:3-11.

143. Rinaldi F, Seguella L, Gigli S, Hanieh PN, Del Favero E, Cantu L, Pesce M, Sarnelli G, Marianecci C, Esposito G, Carafa M. inPentasomes: an innovative nose-to-brain pentamidine delivery blunts MPTP parkinsonism in mice. J Control Release. 2019;294:17-26.

144. Cirillo C, Sarnelli G, Esposito G, Turco F, Steardo L, Cuomo R. S100B protein in the gut: the evidence for enteroglial-sustained intestinal inflammation. World J Gastroenterol. 2011;17:1261-6.

145. Seguella L, Rinaldi F, Marianecci C, Capuano R, Pesce M, Annunziata G, Casano F, Bassotti G, Sidoni A, Milone M, Aprea
G, de Palma GD, Carafa M, Pesce M, Esposito G, Sarnelli G. Pentamidine niosomes thwart S100B effects in human colon carcinoma biopsies favouring wtp53 rescue. J Cell Mol Med. 2020;24:3053-63.

146. Lourie EM, Yorke W. Studies in chemotherapy. Ann Trop Med Parasitol. 1939;33:289-304.

147. Carton F, Chevalier Y, Nicoletti L, Tarnowska M, Stella B, Arpicco S, Malatesta M, Jordheim LP, Briancon S, Lollo G. Rationally designed hyaluronic acid-based nano-complexes for pentamidine delivery. Int J Pharm. 2019;568:118526.

148. Stella B, Andreana I, Zonari D, Arpicco S. Pentamidine-loaded lipid and polymer nanocarriers as tunable anticancer drug delivery systems. J Pharm Sci. 2020;109:1297-302.

149. Merian J, De Souza R, Dou Y, Ekdawi SN, Ravenelle F, Allen C. Development of a liposome formulation for improved biodistribution and tumor accumulation of pentamidine for oncology applications. Int J Pharm. 2015;488:154-64.

150. Stephen S, Gorain B, Choudhury H, Chatterjee B. Exploring the role of mesoporous silica nanoparticle in the development of novel drug delivery systems. Drug Deliv Transl Res. 2021.

151. Peretti E, Miletto I, Stella B, Rocco F, Berlier G, Arpicco S. Strategies to obtain encapsulation and controlled release of pentamidine in mesoporous silica nanoparticles. Pharmaceutics. $2018 ; 10$.

152. Costanzo M, Vurro F, Cisterna B, Boschi F, Marengo A, Montanari E, Meo CD, Matricardi P, Berlier G, Stella B, Arpicco S, Malatesta M. Uptake and intracellular fate of biocompatible nanocarriers in cycling and noncycling cells. Nanomedicine (Lond). 2019;14:301-16.

153. Her S, Cui L, Bristow RG, Allen C. Dual action enhancement of gold nanoparticle radiosensitization by pentamidine in triple negative breast cancer. Radiat Res. 2016;185:549-62.

Publisher's Note Springer Nature remains neutral with regard to jurisdictional claims in published maps and institutional affiliations. 